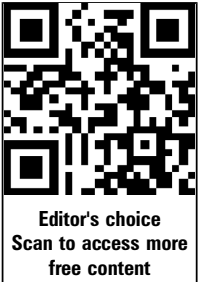

- Additional material is published online only. To view please visit the journal online (http://dx.doi.org/10.1136/ bjsports-2014-093466).

${ }^{1}$ Duke Physical Therapy, Duke University School of Medicine, Durham, North Carolina, USA ${ }^{2}$ Department of Epidemiology, University of North Carolina, Chapel Hill, North Carolina, USA

${ }^{3}$ Duke University, Medical Center Library, Durham, North Carolina, USA

\section{Correspondence to} Dr Adam P Goode, Duke Physical Therapy, Duke University School of Medicine, 2200 West Main Street, Durham, NC 27705, USA; adam.goode@duke.edu

This work was presented at the North Carolina Physical Therapy Association Annual Chapter Meeting 11 October 2013 in Asheville, North Carolina, USA.

Accepted 26 August 2014 Published Online First 16 September 2014

\title{
Eccentric training for prevention of hamstring injuries may depend on intervention compliance: a systematic review and meta-analysis
}

\author{
Adam P Goode, ${ }^{1}$ Michael P Reiman, ${ }^{1}$ Lloyd Harris ${ }^{1}$ Lucia DeLisa, ${ }^{1}$ Aaron Kauffman, \\ David Beltramo, ${ }^{1}$ Charles Poole, ${ }^{2}$ Leila Ledbetter, ${ }^{3}$ Andrea B Taylor ${ }^{1}$
}

\begin{abstract}
Background Hamstring injury is a prevalent muscle injury in sports. Inconclusive evidence exists for eccentric hamstring strengthening to prevent hamstring injuries. One reason for this discrepancy may be the influence intervention non-compliance has on individual study estimates, and therefore pooled estimates.
\end{abstract}

Objective This systematic review aims to determine the effect of eccentric hamstring strengthening on the risk of hamstring injury and quantitatively explores the impact of intervention non-compliance on the precision, heterogeneity and strength of pooled estimates.

Methods A computer-assisted literature search of Medline, CINAHL, Cochrane, EMBASE, AMED, SportDiscus and PEDro databases was conducted with keywords related to eccentric strengthening and hamstring injury. The search was conducted from the end of a previous comprehensive review forward (1 December 2008 to 31 December 2013). Randomeffects models were used for both main effects and a sensitivity analysis. Pooled estimate precision was measured with a confidence limit ratio (confidence limit ratio $(C L R)$; upper limit divided by the lower limit) and heterogeneity was assessed with $\mathrm{I}^{2}$, Cochrane's-Q and $\tau^{2}$. A protocol was not registered for this review.

Results Four out of 349 studies met the inclusion criteria. In main effects analysis, eccentric hamstring training did not reduce the risk of hamstring injury (risk ratio $[R R]=0.59((95 \% \mathrm{Cl} 0.24$ to 1.44$))$. This estimate was imprecise $(C L R=6.0)$ with significant heterogeneity ( $p$ value $0.02,69.6 \%$ variation and $t^{2}=0.57$ ). Subjects compliant with eccentric strengthening had a significant $(\mathrm{RR}=0.35((95 \% \mathrm{Cl} 0.23$ to 0.55$))$ reduction in hamstring injuries. This estimate was precise $(C L R=2.4)$ and homogenous ( $p$ value $=0.38,2.8 \%$ variation and $\mathrm{t}^{2}=0.007$ ).

Conclusions The null-biased effect in using intent-totreat methods from intervention non-compliance has a substantial impact on the precision, heterogeneity and the direction and strength of pooled estimates. Eccentric strengthening, with good compliance, appears to be successful in prevention of hamstring injury.

\section{INTRODUCTION}

Hamstring strains are the most prevalent muscle CrossMark

To cite: Goode AP, Reiman MP, Harris L, et al. Br J Sports Med 2015:49:349-356 injuries reported in sport. These injuries alone have accounted for between $6 \%$ and $29 \%$ of all reported injuries in football, Australian Rules football, rugby union, basketball, cricket and track sprinters. ${ }^{1-9}$ Hamstring injuries also have a high recurrence rate. $^{2}{ }^{10-12}$ Significant research effort over the past 10 years has been directed at injury prevention and return to sport after hamstring injury. ${ }^{13-23}$ Continued high prevalence of injury rates from 2001 to $2008^{24}$ suggest that traditional prevention and rehabilitation programmes have been ineffective. $^{25}$

Eccentric training for injury prevention has been suggested as a means of decreasing the high prevalence of these injuries, ${ }^{13}$ 19-22 with even more promising results than those observed with concentric training. ${ }^{26}$ In fact, as pointed out by Thorborg, ${ }^{27}$ the number needed to treat (NNT) of 13 to prevent 1 acute hamstring injury (new or recurrent) is considerably more impressive than the NNT of approximately 90 for neuromuscular training programmes for the prevention of anterior cruciate ligament injury. $^{28}$ While the precise mechanism by which eccentric hamstring exercise is effective is not fully understood, ${ }^{29}$ and continues to be debated, ${ }^{29}{ }^{30}$ the potential benefit of eccentric training has been recognised. ${ }^{27}$

Clinical trials commonly implement intention to treat (ITT) analyses to compare end points regardless of postrandomisation compliance. ${ }^{31}$ This type of analysis tends to underestimate the true effect when participants are not compliant and the treatment is effective. ${ }^{32}$ Failure to comply can be especially problematic with ITT methods because as compliance decreases, effectiveness also decreases regardless of the efficacy of the treatment. ${ }^{32}$ Non-compliance rates as high as 20 and $22 \%$ using ITT methods have produced substantial bias in estimating treatment effects. ${ }^{33}$ Commonly, investigators will recognise non-compliance and report per-protocol, or analysis of the 'complier' groups separate. ${ }^{34}$ This type of subgroup analysis can also be problematic since the baseline risk of compliers and non-compliers may be different, which has the potential to create a selection bias that overestimates the true effect. ${ }^{35}$ Decreased compliance with eccentric training for the prevention of hamstring injuries has been recognised in some, but not all, reported randomised trials ${ }^{20} 21$ and is suspected to be one reason for drastically differing results. ${ }^{19-22}$ These differing results have led to inconclusive evidence to support eccentric hamstring strengthening to prevent hamstring injury in pooled analysis. ${ }^{36}$ The purpose of this review is twofold: (1) systematically review the literature on randomised clinical trials (RCT) examining the effect of eccentric hamstring strengthening on prevention of hamstring injury among athletes, and (2) quantitatively explore the impact of intervention compliance on the precision, heterogeneity and both strength and direction of pooled study estimates. 


\section{METHODS}

\section{Study design}

The design of this systematic review was developed using the guidelines of the Preferred Reporting Items for Systematic Reviews and Meta-Analyses (PRISMA). The PRISMA statement includes a 27 -item checklist that is designed to be used as a basis for reporting systematic review of randomised trials. ${ }^{37}$ A review protocol was not registered for this review.

\section{Search strategy}

Identification and selection of the literature

A systematic, computerised search of the literature in PubMed, CINAHL, EMBASE, Cochrane, AMED, SportDiscus and PEDro was conducted by a research and education librarian (LL) with controlled vocabulary and keywords related to eccentric strengthening and hamstring injury. This coauthor did not participate in aspects of screening, full-text review or data abstraction. Our search time-frame was restricted from 1 December 2008 to 31 December 2013 due to a previous comprehensive review also investigating this topic from 1966 to December $2008 .^{36}$ The PubMed search strategy used for the current study can be found in our online supplementary appendix. We developed our search strategy from a previous comprehensive review's ${ }^{36}$ search strategy using updated Medical Subject Headings (MeSH) terms, included terms specific to eccentric strengthening and included terms to search for any systematic reviews or meta-analysis published that may be similar to our work. The search strategy for this previous comprehensive review can be found in the online supplementary appendix of their publication. ${ }^{36}$ The reference lists of all selected publications were checked to retrieve relevant publications that were not identified in the computerised search. References of screened and included articles, abstracts and available conference proceedings were also hand searched by one of the authors (MPR) and included publications, posters, abstracts or conference proceedings. To identify relevant articles, two reviewers independently screened titles and abstracts of all identified citations (MPR and APG). Full-text articles were retrieved if the abstract provided insufficient information to establish eligibility or if the article had passed the first eligibility screening.

\section{Selection criteria}

All articles examining eccentric injury prevention for the hamstrings were eligible for full-text review. An article was eligible for study inclusion if it met all of the following criteria: (1) the article was a RCT, (2) included athletes (participation in organised sports) of either sex who were at risk of incurring hamstring injuries and not participating in a hamstring rehabilitation programme, (3) athletes with and without a history of hamstring injury, (4) included eccentric exercise intervention in comparison with a control or alternative interventions for the prevention of hamstring injuries, (5) study was required to report on the outcome of incidence of hamstring injury and 6) compliance with the intervention was either reported or could be calculated.

An article was excluded if: (1) included athletes with existing, or under treatment for, lower-limb musculoskeletal injuries, (2) reports focused on children below the age of 10 years, or (3) the article was not in English.

All criteria were independently applied by two reviewers (MPR and APG) to the full text of the articles that passed the eligibility screening of titles and abstracts. Any disagreement was resolved by discussion.
Quality assessment

The methodological quality of individual studies was assessed using the Physiotherapy Evidence Database (PEDro) scale. ${ }^{38}$ Results from individual study analysis of quality were used to identify common areas of methodological weaknesses across studies. Two reviewers (MPR and LH) independently assessed the quality of the studies. Disagreement or ambiguous issues were resolved by discussion with an independent assessor (APG).

PEDro uses 11 criteria, and reviewed studies were awarded one point for each criterion that was clearly satisfied, for a potential maximum value of 11 points. Criteria included: (1) eligibility criteria reported; (2) random assignment; (3) concealed allocation; (4) groups similar at baseline regarding most important prognostic indicator; 5) blinding of participants; (6) blinding of therapists who administered the therapy; (7) blinding of assessors who measured key outcome; (8) measures of at least one key outcome were obtained from more than $85 \%$ of initial participants; (9) all participants received treatment or control condition as allocated; (10) results of between-group statistical comparisons are reported and (11) study provides point measures and measures of variability for at least one key outcome. ${ }^{38}$

\section{Statistical analysis}

Data, including counts and risk or rate ratios with corresponding CIs, were extracted manually from included studies by two separate authors (LD and AK) and confirmed by a third author (MPR). DerSimonian and Laird ${ }^{39}$ random effects models were used for all pooled analyses, which incorporate both betweenstudy and within-study heterogeneity, to produce summary pooled risk ratios (RR's) and 95\% CIs. We used this model to be consistent with a previously reported review on the same intervention and outcome. ${ }^{36}$ Heterogeneity test statistics and their $\mathrm{p}$ values were used to assess consistency of reported RR's across studies. I-squared statistic $\left(\mathrm{I}^{2}\right)$ was used to describe the percentage of total variation across studies due to heterogeneity rather than chance alone with values of $>50 \%$ to indicate substantial heterogeneity. ${ }^{40}$ Significant heterogeneity was indicated with a $p<0.10$. A higher $p$ value was chosen to test for heterogeneity since these tests have low power particularly when there are few studies analysed. ${ }^{41}$ The $\tau^{2}$ is reported to describe the pooled among-study variance of true effects, thereby reflecting the magnitude of heterogeneity. ${ }^{42}$ Precision of individual and overall pooled study estimates was determined with a confidence limit ratio (CLR). This ratio is the upper confidence limit divided by the lower confidence limit with results closer to " 1 " indicating greater relative precision. ${ }^{43}$ Publication bias was not formally assessed due to low statistical power with few included studies. All analyses were conducted in Stata 12 (Stata Corp, College Station, Texas, USA by one of the authors (APG).

\section{Sensitivity analyses}

A simple sensitivity analysis was conducted to compare the treatment effects analysing estimates from compliant subjects (ie, per protocol analyses). These analyses represent the effect of eccentric hamstring strengthening on hamstring injury with good intervention compliance. Estimates and 95\% CIs were abstracted from articles reporting analysis of complier groups separately. These estimates and 95\% CI's were entered into our statistical software. This software recalculates the SDs resulting in slight differences in the $95 \%$ CI's. The magnitude of difference is less than a 100th of a decimal point. DerSimonian and Laird $^{39}$ random effects models were employed in the same 
fashion as the main effects analysis above. Measures and criteria for heterogeneity and precision were also identical to above. Both complier analysis and ITT individual study estimates were qualitatively compared and the overall pooled estimates between the main effects and the sensitivity analysis were compared with a change-in-estimate formula (|lnRRmain effectslnRRsensitivity analysis |).

\section{RESULTS}

\section{Selection of studies}

Three hundred forty-nine titles were identified through database and reference searches. Eight abstracts then were assessed for eligibility for inclusion, resulting in four appropriate studies (1229 athletes). ${ }^{19-22}$ Three of the four full text articles screened for inclusion were excluded due to inability to determine either study compliance and/or intervention outcomes. ${ }^{44-46}$ Only one additional study ${ }^{22}$ was discovered since the previous published review. $^{36}$ The number of athletes in the studies ranged from $30^{19}$ to $942 .^{22}$ Three of the studies ${ }^{19} 2122$ investigated various levels of soccer players, and the fourth study ${ }^{20}$ investigated Australian Rules football players. One study ${ }^{19}$ utilised a "Yo-Yo" flywheel ergometer, while the other three studies ${ }^{20-22}$ implemented the Nordic hamstring exercise as the method of eccentric hamstring strengthening. The process of study selection and the number of studies excluded at each stage, with reasons for exclusion is available in figure 1. A description of the included studies populations, interventions, comparators and outcome measures are found in table 1 .

\section{Quality of studies}

The scores on each of the 11 criteria and total scores for each study are presented in table 2 . One study ${ }^{22}$ scored 9/11, second study ${ }^{19}$ scored $8 / 11$, third study ${ }^{20}$ scored $5 / 11$ and the fourth study $^{21}$ scored $3 / 11$ on PEDro scoring.

\section{Summary of individual studies}

Table 3 provides the reported compliance, adverse events, individual study estimates and measure of precision for each of the included articles. Reported compliance was poor in the Gabbe ${ }^{20}$ and Engebretsen ${ }^{21}$ studies, with $50 \%$ of enrolled athletes declining to participate $e^{20}$ and $63 \%$ reporting not being compliant with any exercise, ${ }^{21}$ respectively. Both the Askling et $a l^{19}$ and Petersen et $a l^{22}$ studies reported good compliance with over $90 \%$ of the athletes having completed the intervention. Delayed onset muscle soreness (DOMS) was by far the primary reason for adverse event reporting. The individual study estimates from the Askling $e t a l^{19}$ and Peterson et $a l^{22}$ studies were identical, indicating a $70 \%$ reduction in hamstring injuries from eccentric

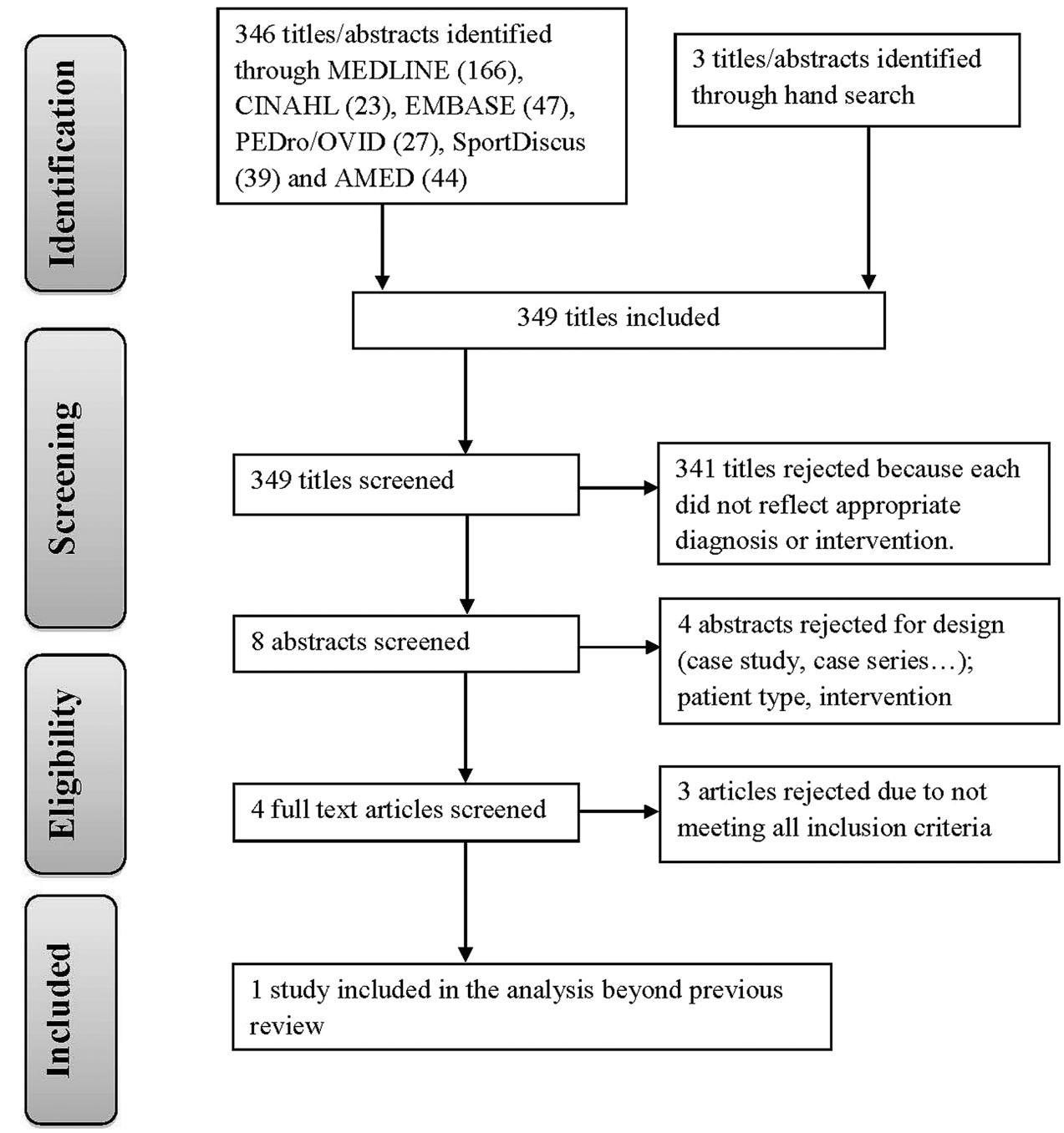

Figure 1 Preferred Reporting Items for Systematic Reviews and Meta-Analyses (PRISMA) flow diagram for study inclusion. 
Table 1 Summary of athletes, interventions, comparators and injuries of included studies

\begin{tabular}{|c|c|c|c|c|c|}
\hline Study & Athletes & Interventions & Comparator(s) & Number of injuries & Outcome recording \\
\hline Askling et $a l^{19}$ & $\begin{array}{l}30 \text { male soccer athletes from } 2 \text { premier } \\
\text { league teams in Sweden. Goalkeepers, } \\
\text { injured players and players with } \\
\text { chronic hamstring problems were } \\
\text { excluded from the study }\end{array}$ & $\begin{array}{l}\text { "Yo-Yo" flywheel ergometer ( } n=15) .16 \text { sessions of } \\
\text { specific hamstring length training, every } 5 \text { th day for } \\
\text { the first } 4 \text { weeks, and every } 4 \text { th day during the last } \\
6 \text { weeks (total of } 10 \text { training weeks) }\end{array}$ & $\begin{array}{l}\text { The training and control groups }(n=15) \\
\text { followed the same protocol with the only } \\
\text { exception being that the training group } \\
\text { received additional specific hamstring training } \\
\text { during phase } 1 \text {. } \\
\text { Intervention was for } 10 \text { weeks period }\end{array}$ & $\begin{array}{l}\text { Intervention group: } \\
3 / 15 \text { athletes } \\
\text { Control group: } \\
10 / 15 \text { athletes }\end{array}$ & $\begin{array}{l}\text { Compliance and side effects: (muscle } \\
\text { soreness/symptoms in training) recorded } \\
\text { individually by athlete. } \\
\text { Injuries: recorded by team training staff } \\
\text { (not part of study) }\end{array}$ \\
\hline Gabbe et $a l^{20}$ & $\begin{array}{l}220 \text { Australian Rules Football athletes. } \\
\text { Athletes were excluded if they had a } \\
\text { hamstring injury at the time of } \\
\text { recruitment }\end{array}$ & $\begin{array}{l}\text { Nordic Hamstring Exercise }(\mathrm{n}=114) \text {. } 12 \text { sets } \times 6 \text { reps } \\
\text { with a } 10 \mathrm{~s} \text { rest in between reps and } 2-3 \text { rest } \\
\text { between sets. } 5 \text {-session programme over a } 12 \text {-week } \\
\text { period. The first three sessions were } 2 \text { weeks apart } \\
\text { during the last } 6 \text { weeks of preseason. The final two } \\
\text { sessions were } 3 \text { weeks apart during the first weeks } \\
\text { of the season }\end{array}$ & $\begin{array}{l}\text { Control group ( } n=106) \text { : gastrocnemius stretch } \\
\text { in standing }(30 \mathrm{~s}) \text {; hip flexor stretch in } \\
\text { kneeling }(30 \mathrm{~s}) \text {; hamstring stretch in supine } \\
(30 \mathrm{~s}) \text {; hamstring stretch in sitting }(30 \mathrm{~s}) \text {; } \\
\text { lumbar spine rotation in supine }(15 \mathrm{~s}) \text {. } \\
\text { Interventions were prescribed } 5 \text { times during } \\
\text { one 12-week period. }\end{array}$ & $\begin{array}{l}\text { Intervention group: } \\
\text { 10/114 athletes } \\
\text { Control group: } \\
8 / 106 \text { athletes }\end{array}$ & $\begin{array}{l}\text { Compliance and side effects: Each session } \\
\text { was supervised by study personnel. } \\
\text { Injuries: monitored by club officials and } \\
\text { medical staff. Injury surveillance form } \\
\text { filled out/injury recorded by team } \\
\text { physiotherapist not blinded to allocation } \\
\text { of player to specific group }\end{array}$ \\
\hline Engebretsen et $a l^{21}$ & $\begin{array}{l}37 \text { male soccer athletes from the } 1 \text { st, } \\
2 \text { nd, or top of the 3rd Norwegian } \\
\text { League. } \\
\text { Athletes divided into high (previous } \\
\text { injury) and low (no previous injury) risk } \\
\text { groups }\end{array}$ & $\begin{array}{l}\text { Nordic Hamstring exercise }(\mathrm{n}=24) \text {. Week 1: } \\
\text { ( } 1 \text { session per week with } 2 \text { sets of } 5 \text { reps), week 2: } \\
\text { ( } 2 \text { sessions per week with } 2 \text { sets of } 6 \text { reps), week } 3 \text { : } \\
\text { ( } 3 \text { sessions per week with } 3 \text { sets of } 6-8 \text { reps), } \\
\text { week } 4 \text { : ( } 3 \text { sessions per week with } 3 \text { sets of } 8-10 \\
\text { reps), weeks } 5-10 \text { : ( } 3 \text { sessions per week with sets } \\
\text { of } 12,10 \text {, and } 8 \text { reps) }\end{array}$ & $\begin{array}{l}\text { Control group }(n=13) \text { continued with their } \\
\text { normal training schedule throughout the } \\
\text { 10-week cycle }\end{array}$ & $\begin{array}{l}\text { Intervention group: } \\
5 / 24 \text { athletes } \\
\text { Control group: } 1 / 13 \\
\text { athletes }\end{array}$ & $\begin{array}{l}\text { Compliance and side effects: Individual } \\
\text { players recorded exercises performed. } \\
\text { Injuries: team physical therapist instructed } \\
\text { exercises and recorded injuries (blinding } \\
\text { unknown, but assumed they were not } \\
\text { since they provided intervention, etc.) }\end{array}$ \\
\hline Petersen et $a^{22}$ & $\begin{array}{l}942 \text { Danish professional and amateur } \\
\text { soccer athletes. Detail of previous } \\
\text { hamstring injuries during past } \\
12 \text { months was recorded }\end{array}$ & $\begin{array}{l}\text { Nordic Hamstring Exercise ( } \mathrm{n}=461) \text {. Along with } \\
\text { normal training performed } 27 \text { sessions of Nordic } \\
\text { hamstring exercise over } 10 \text { week span. Week } 1 \text { : } \\
\text { ( } 1 \text { session per week with } 2 \text { sets of } 5 \text { reps), week } 2 \text { : } \\
\text { ( } 2 \text { sessions per week with } 2 \text { sets of } 6 \text { reps), week } 3 \text { : } \\
\text { ( } 3 \text { sessions per week with } 3 \text { sets of } 6-8 \text { reps), } \\
\text { week } 4 \text { : ( } 3 \text { sessions per week of } 8-10 \text { reps), week } \\
5-10 \text { : ( } 3 \text { sessions per week with } 3 \text { sets of } 12-10-8 \\
\text { reps). After week } 10 \text { the players continued to do } \\
1 \text { session per week of } 3 \text { sets of } 12-10-8 \text { reps }\end{array}$ & $\begin{array}{l}\text { Control group }(n=481) \text {. Continued with their } \\
\text { normal training schedule throughout the } 10 \text { - } \\
\text { week cycle }\end{array}$ & $\begin{array}{l}\text { Intervention group: } \\
15(12 \text { new and } 3 \\
\text { recurrent)/461 } \\
\text { athletes } \\
\text { Control group: } \\
(52 \text { ( } 32 \text { new and } 20 \\
\text { recurrent)/481 } \\
\text { athletes }\end{array}$ & $\begin{array}{l}\text { Compliance and side effects: Supervised } \\
\text { by team coaches. } \\
\text { Injuries: team physiotherapist recorded } \\
\text { injuries. Recurrence of previously recorded } \\
\text { injuries in registration period was not } \\
\text { included to avoid recording same injury } \\
\text { more than once }\end{array}$ \\
\hline
\end{tabular}


Table 2 The PEDro quality assessment of individual studies

\begin{tabular}{|c|c|c|c|c|c|c|c|c|c|c|c|c|}
\hline \multirow[b]{2}{*}{ Journal article } & \multicolumn{12}{|c|}{ PEDro scale } \\
\hline & 1 & 2 & 3 & 4 & 5 & 6 & 7 & 8 & 9 & 10 & 11 & Score \\
\hline Askling et $a l^{19}$ & + & + & - & + & - & - & + & + & + & + & + & 8 \\
\hline $\begin{array}{l}\text { Engebretsen } \\
\text { et } a l^{21}\end{array}$ & + & + & - & + & - & - & - & - & - & + & + & 5 \\
\hline Gabbe et $a l^{20}$ & + & + & - & + & - & - & - & - & + & + & + & 6 \\
\hline Petersen et $a l^{22}$ & + & + & + & + & - & - & + & + & + & + & + & 9 \\
\hline \multicolumn{13}{|c|}{$\begin{array}{l}\text { 1. Eligibility criteria were specified. } \\
\text { 2. Subjects were randomly allocated to groups. } \\
\text { 3. Allocation was concealed. } \\
\text { 4. Groups were similar at baseline regarding most important prognostic indicators. } \\
\text { 5. Blinding of all participants. } \\
\text { 6. Blinding of therapists who administered the therapy. } \\
\text { 7. Blinding of all assessors who measured at least one key outcome. } \\
\text { 8. Measures of at least one key outcome were obtained from more than } 85 \% \text { of the } \\
\text { participants. } \\
\text { 9. All subjects for whom outcome measures were available received the treatment or } \\
\text { control condition as allocated. } \\
\text { 10. Results of between-group statistical comparisons are reported for at least one key } \\
\text { outcome. }\end{array}$} \\
\hline
\end{tabular}

training with the Peterson et $a l^{22}$ study having greater precision due to the increased sample size. Gabbe $e t a l^{20}$ and Engebretsen et $a l^{21}$ both reported increased risk of hamstring injuries from eccentric training that were not statistically significant and substantially imprecise.

\section{Meta-analysis findings}

Individual study estimates reporting ITT analysis, overall pooled estimate and measures of heterogeneity are illustrated in figure 2. This figure represents each included study's reported
RR and 95\% CI of hamstring injury following eccentric training. The diamond represents the overall summary estimate and the width of the diamond represents the overall point estimate 95\% CI. The overall pooled estimate from the main effects analysis was 0.59 (95\% CI 0.24 to 1.44$)$ with a CLR of 6 . Significant heterogeneity (heterogeneity $p$ value $=0.02$ ) was found with $69.6 \%$ of the variation in the overall pooled RR attributable to heterogeneity and $\tau^{2}=0.542$.

Figure 3 illustrates the findings from the sensitivity analysis that included individual study estimates with ITT estimates from Askling $e t a l^{19}$ and Peterson et $a l^{22}$ and per protocol analysis from both Gabbe et $a l^{20}$ and Engebretsen et al. ${ }^{21}$ These pooled studies were also homogeneous (heterogeneity $\mathrm{p}$ value $=0.38$ ) with $2.8 \%$ of the variation in the overall pooled RR attributable to heterogeneity and $\tau^{2}=0.007$. The overall pooled estimate was 0.35 (95\% CI 0.23 to 0.55 ) with a CLR of 2.39 indicating a $65 \%$ reduction in the risk of hamstring injury from eccentric hamstring strengthening.

There was a substantial increase in the strength of the overall pooled estimate from the sensitivity analysis when compared with the main effect analysis (ie, 0.59 to 0.35 ) that was down and away from the null value. This difference represented a $52 \%$ change-in-estimate from the main effect to the sensitivity analysis.

\section{DISCUSSION}

This systematic review assessed the literature on eccentric strengthening as a prevention measure of future hamstring injury and explored the effect that compliance may have on the precision, heterogeneity and both the strength and direction of pooled study estimates. Our search yielded four studies ${ }^{19-22}$ that met our inclusion/exclusion criteria. Using data from these sources we found a stronger effect towards injury prevention than the previously reported review. ${ }^{36}$ Similar to this previous

Table 3 Reported compliance, adverse events, individual study estimates and precision of included studies

\begin{tabular}{|c|c|c|c|c|c|c|}
\hline Study & Reported compliance & $\begin{array}{l}\text { Reported adverse } \\
\text { events (number of } \\
\text { events) }\end{array}$ & $\begin{array}{l}\text { ITT individual study } \\
\text { estimates } \\
\text { RR }(95 \% \mathrm{CI})\end{array}$ & $\begin{array}{l}\text { Precision } \\
\text { (CLR) }\end{array}$ & $\begin{array}{l}\text { Per protocol } \\
\text { individual study } \\
\text { estimates } \\
\text { RR }(95 \% \mathrm{CI})\end{array}$ & $\begin{array}{l}\text { Precision } \\
\text { (CLR) }\end{array}$ \\
\hline $\begin{array}{l}\text { Askling } \\
\text { et } a l^{19}\end{array}$ & $100 \%$ & DOMS ( $\mathrm{n}=11$ athletes) & 0.30 (0.10 to 0.88$)$ & 8.8 & NA & NA \\
\hline Gabbe et $a l^{20}$ & $\begin{array}{l}\text { Intervention group: } 50 \% \text { decline in participation } \\
\text { rate from session } 1 \text { to session } 2 \\
\text { Control group: } 10 \% \text { decline in participation rate } \\
\text { from session } 1 \text { to session } 2 \\
<10 \% \text { of athletes participated in season session } 2 \\
30 \% \text { of consenting athletes ( } n=66) \text { failed to } \\
\text { complete one session, while } 103(46.8 \%) \\
\text { completed at least two sessions }\end{array}$ & $\begin{array}{l}\text { DOMS was primary } \\
\text { reason reported for lack } \\
\text { of compliance }(n=N R)\end{array}$ & 1.15 (0.48 to 2.83$)$ & 5.9 & $0.30(0.08$ to 1.12$)$ & 14.0 \\
\hline $\begin{array}{l}\text { Engebretsen } \\
\text { et } a l^{21}\end{array}$ & $\begin{array}{l}\text { Only } 21.1 \% \text { ( } 12 \text { athletes) completed } 20 \text { or more } \\
\text { training sessions } \\
63.2 \% \text { of players reported not having performed } \\
\text { any exercises, } 7.9 \% \text { of athletes performed } 1-9 \\
\text { sessions and } 7.9 \% \text { of athletes performed } 10-19 \\
\text { sessions }\end{array}$ & DOMS ( $\mathrm{n}=\mathrm{NR})$ & 2.71 (0.35 to 20.79) & 59.4 & $0.94(0.29$ to 3.07$)$ & 10.6 \\
\hline $\begin{array}{l}\text { Petersen } \\
\text { et }\left.a\right|^{22}\end{array}$ & $\begin{array}{l}\text { Team compliance was an average of } 91 \% \text { of the } \\
\text { intended training sessions performed during the } \\
10 \text {-week midseason period ( } 8 \% \text { dropout rate in } \\
\text { intervention group and } 9 \% \text { dropout rate in control } \\
\text { group) } \\
\text { Compliance was not measured after the first } \\
10 \text { weeks }\end{array}$ & $\begin{array}{l}\text { DOMS ( } n=\text { "most players } \\
\text { in the intervention } \\
\text { group") }\end{array}$ & $0.30(0.17$ to 0.53$)$ & 3.1 & NA & NA \\
\hline
\end{tabular}


Figure 2 Forest plot reflecting individual study intent-to-treat analysis estimates and $95 \% \mathrm{Cl}$, an overall pooled estimate (diamond) and $95 \%$ $\mathrm{Cl}$ with heterogeneity statistics $\left(\mathrm{I}^{2}\right.$ and heterogeneity $p$ value).

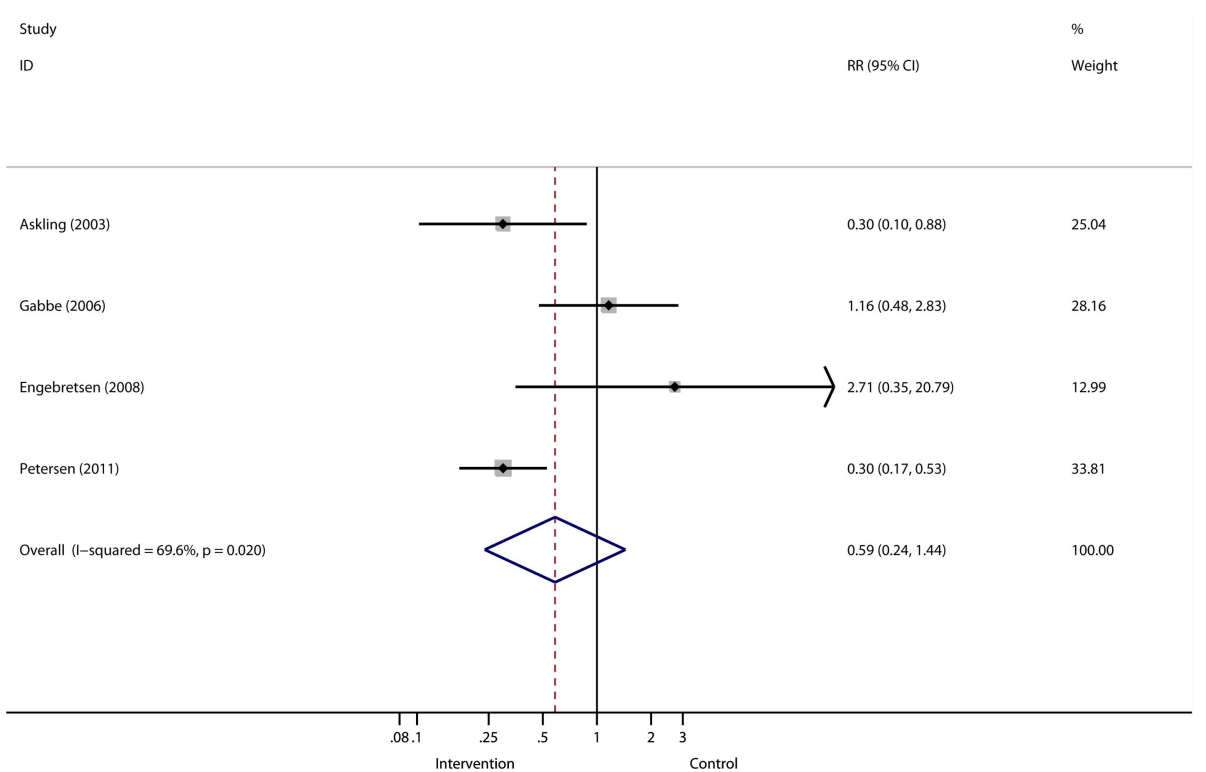

review, our pooled estimate in main effects analysis was not statistically significant. Our sensitivity analysis found that those studies with a large proportion of non-compliance explained the decreased precision and heterogeneity in the main effects analysis.

One additional study by Petersen et $a l^{22}$ has been published on this topic since the 2010 Cochrane Review. ${ }^{36}$ This study differed from the other three included studies in that it utilised a cluster (team) randomised approach; however, the intracluster correlation was taken into account during the analysis. Despite the majority of information (weight) provided by this study to our overall pooled estimate, the addition of the Petersen et $a l^{22}$ study alone continues to support that there is inconclusive evidence for eccentric hamstring strengthening in the prevention of hamstring injury. Our heterogeneity analysis, with the inclusion of this additional study, ${ }^{22}$ continued to indicate significant heterogeneity between studies, which is also consistent with this previous Cochrane Review. ${ }^{36}$ The addition of the Petersen et $a l^{22}$ study, however, did allow for interesting comparisons in our sensitivity analysis to explore the impact of compliance on the overall pooled estimate and heterogeneity.

Our sensitivity analysis yielded several important findings. First, the inclusion of estimates of compliant groups from the Engebretsen $e t a l^{47}$ and Gabbe et $a l^{20}$ studies, together with the estimates of compliant groups from the Askling et $a l^{19}$ and Peterson et $a l^{22}$ studies, yielded a pooled estimate that indicates substantial (65\%) decreased risk of hamstring injury from eccentric training. Interestingly, this is a similar finding to that of Arnason et $a l^{13}$ who also reported a $65 \%$ reduction in hamstring injury from eccentrics in an observational intervention study. The estimate of subjects compliant with the intervention from Gabbe et $a l^{20}$ was identical to the findings of Askling et $a l^{19}$ and Peterson et $a l^{22}$ Similarly, the estimate of the compliant group from Engebretsen et al, ${ }^{21}$ shifted towards a decrease risk of hamstring injury when compared with the ITT estimate from the same study. These are important considerations since one of the main concerns of using complier group or per protocol estimates are that it may lead to an overestimation of the
Figure 3 Forest plot of individual study estimates reflecting good intervention compliance and $95 \% \mathrm{Cl}$ an overall pooled estimate (diamond) and $95 \% \mathrm{Cl}$ and heterogeneity statistics $\left(I^{2}\right.$ and heterogeneity $p$ value).

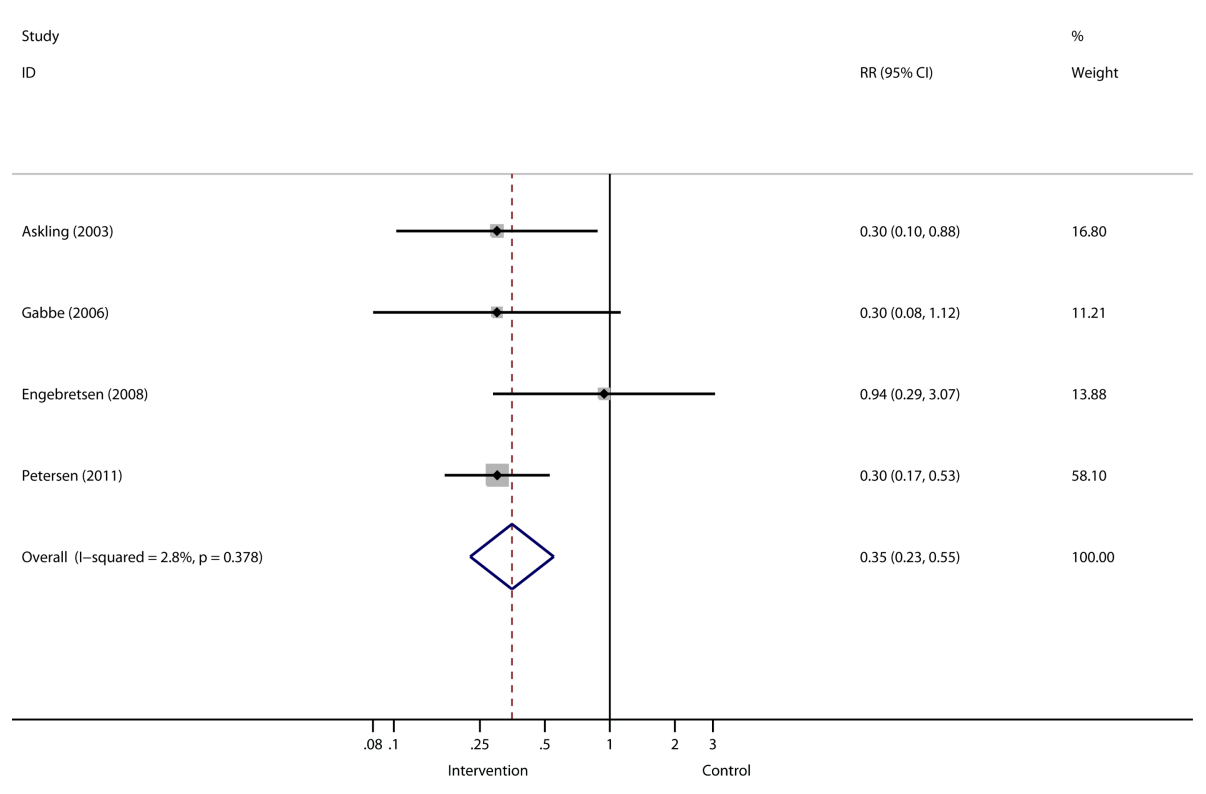


treatment effect. Our overall pooled estimate in the complier estimates analysis, despite the decrease in sample size, demonstrated a substantial improvement in precision relative to the main effect analysis. One reason for the improved precision is the improved reliability and homogeneity of the groups without non-compliers present. Our sensitivity analysis findings may not be sufficient to conclusively indicate that eccentric hamstring strengthening prevents hamstring injury. However, there appears to be growing evidence regarding the effect of eccentric exercise and that intervention compliance may be influential in understanding the true effect in pooled analysis.

Compliance rates differed drastically across the included studies. Askling $e t a l^{19}$ reported excellent compliance measured at the individual athlete level. Although Petersen $e t$ al ${ }^{22}$ report minimal non-compliance (91\% compliance rate) this is unlikely to result in a substantial null-bias effect since the noncompliance in this study was present in both the intervention and control arms of the trial. By contrast, both Engebretsen et $a l^{21}$ and Gabbe et $a l^{20}$ reported a substantial overall study non-compliance rate. The non-compliance in these two studies has the potential to result in a substantial null-biased effect with ITT methods since the rate of non-compliance was greater among the intervention arms of the trial when compared to the control arm. ${ }^{32}$ These findings have the potential to bias not only individual study results but, as demonstrated in this review, the potential to bias pooled overall estimates.

Non-compliance to physiotherapy is not unique to eccentric hamstring training. ${ }^{48-53}$ Commonly described barriers related to exercise non-compliance include pain during exercise, ${ }^{52-55}$ anxiety/confusion regarding the exercise, ${ }^{50} 525455$ low selfefficacy $^{505255}$ and poor social support. ${ }^{52}$ Some of these variables were reported in each of these studies. ${ }^{19-22}$ DOMS, a side effect reported in all four studies, ${ }^{19-22}$ is known to result from eccentric exercise. ${ }^{26}$ In fact, in the Gabbe $e t$ al ${ }^{20}$ study the athletes believed DOMS would increase their risk of future hamstring injury, likely affecting exercise compliance.

Volume of exercise may also result in non-compliance. Two of the studies in this review ${ }^{19}{ }^{22}$ utilised a single exercise for the purpose of hamstring injury prevention. Less time involvement (as with fewer exercises to perform), ${ }^{19} 22$ as well as the benefit of exercising with a partner athlete, ${ }^{56}$ (as with the Nordic hamstring exercise), may have more clinical applicability and appeal for broad scale injury prevention application.

Direct supervision was employed in two of the studies, ${ }^{20} 22$ although athlete attendance was not mandatory for preseason training in one of them. ${ }^{20}$ Compliance related to monitoring by team officials and coaches did not appear to favour improved outcomes in one of the low-quality/poorer compliance studies, ${ }^{20}$ but in the highest quality study (with excellent compliance) in this review ${ }^{22}$ team coaches appeared to have a positive influence on compliance. Encouragement from the coaching staff may be especially meaningful in preseason training, as this is likely the ideal time to implement prevention strategies since a number of training sessions were required to gain the injury preventive effect. ${ }^{22}$ Although each athlete was individually responsible for his own training in the other two studies, ${ }^{19} 21$ only one of the studies ${ }^{19}$ reported that a majority of the players $(11 / 15)$ considered the training meaningful and were positive towards continuation of the training after study completion. Moreover, exercises carried out by each player independently may not be as effective as when they are performed under qualified supervision, ${ }^{57}$ not only due to lower compliance, but also the fact that the quality of the exercises performed cannot be ensured. ${ }^{21}$
Improving exercise compliance is multidimensional. ${ }^{51} \quad 54$ Addressing the issues outlined above is likely to improve compliance prior to and during an injury prevention study. Implementation of coaching workshops, ${ }^{58}$ policy enactment by sport organisations due to demonstrated benefit of such programmes, ${ }^{59}$ emphasising performance-enhancement benefits to the athlete ${ }^{59}$ and focusing on athletes at risk of injury for each specific sport ${ }^{8} 9$ are additional means of improving injury prevention exercise compliance.

In addition to non-compliance, a concern of the studies in this review was the method of randomisation and the potential risk of contamination. Three of the studies randomised the athletes within the same team, ${ }^{19-21}$ leading to the potential for contamination. A potentially bigger risk of contamination was the fact that 19 of the 31 teams in the Engebretsen $e$ a $l^{21}$ study did team-based preventive exercises similar to those employed in the study on a regular basis throughout the preseason. The potential for athletes in the control group to have also shown benefit from prevention training must be considered in this study. Only the Petersen et al ${ }^{22}$ study randomised by team, potentially leading to social support within the team as a positive compliance factor. Although the potential risk of contamination exists it is unlikely to result in the substantial between-study estimate differences especially in the presence of significant non-compliance.

Our review is not without limitations. Although we conducted a thorough search utilising multiple databases, our search was limited to the English language, potentially excluding relevant studies. There are concerns with including estimates from compliant subjects (ie, per protocol) along with ITT estimates in the sensitivity analysis as these estimates of compliant subjects may overstate the true effect. However, in this particular case, there appears to be considerable consistency when analysing estimates reported from studies with good compliance. Moreover, our review found a substantial improvement in the statistical homogeneity and relative precision of the overall pooled estimate in the sensitivity analysis with compliant groups only. Other factors related to the reporting of non-compliance may also lead to bias and influence individual study and pooled estimates; however, we were unable to assess these details finely in these analyses. Analyses of groups with good compliance, in this particular case, appear to reflect the effect of eccentric hamstring exercise on the prevention of hamstring injury among those athletes performing the exercise rather than effectiveness of the delivery method represented in ITT methods.

\section{CONCLUSION}

Intent-to-treat is the preferred method of determining effectiveness of interventions in RCT's. However, this method is subject to null-bias when there is substantial non-compliance. When non-compliance is recognised within studies, authors would benefit from assessing the impact of compliance by analysing compliant groups separately, especially in the presence of differential non-compliance between study arms. These estimates may be compared with prior studies to determine if non-compliance is producing a substantial null-bias effect. In producing overall pooled estimates with studies examining the effect of eccentric exercise on hamstring injury, intervention non-compliance appears to produce a substantial null-bias effect. Non-compliance, therefore, may have important implications in meta-analysis conclusions and recommendations for implementation of eccentric strengthening for hamstring injury prevention. Eccentric strengthening with good compliance appears to be an influential factor in successful prevention of hamstring 
injury. Future studies and training programmes should focus on the implementation of eccentric strength training with an emphasis of successful compliance.

\section{What is already known on this topic?}

- Eccentric hamstring strengthening has shown the potential to decrease injury, although not all studies are conclusive.

- There continues to be inconclusive evidence regarding eccentric hamstring strengthening in randomised controlled trials implementing intent-to-treat analysis.

\section{What this study adds?}

- Decreased intervention compliance is a key reason for this inconclusive evidence.

- When participants are compliant with eccentric hamstring strengthening there is a significant and strong $65 \%$ decreased risk of hamstring injury.

- The primary and consistent reason for individual study reported decreased intervention compliance is the side effect of delayed onset muscle soreness.

\section{Recommendations are as follows}

- The use of eccentric strengthening should be implemented on a wide-scale basis for the potential prevention of future hamstring injury.

- Implementation of such a programme requires athlete compliance.

- To improve athlete compliance, exercise implementation should be applicable to entire team.

Contributors APG, MPR, LH, LD, AK, DB, LL, CP and AT planned, conducted and reported the work described in the article.

APG: had access to all the data and was responsible for conducting and reporting the statistical analysis. All authors contributed significantly to this work and authorship of this manuscript. Both APG and MPR contributed equally to the writing of this manuscript.

\section{Competing interests None.}

Provenance and peer review Not commissioned; externally peer reviewed.

\section{REFERENCES}

1 Woods C, Hawkins RD, Maltby S, et al. The Football Association Medical Research Programme: an audit of injuries in professional football-analysis of hamstring injuries. Br J Sports Med 2004;38:36-41.

2 Orchard J, Seward H. Epidemiology of injuries in the Australian Football League, seasons 1997-2000. Br J Sports Med 2002;36:39-44.

3 Meeuwisse WH, Sellmer R, Hagel BE. Rates and risks of injury during intercollegiate basketball. Am J Sports Med 2003;31:379-85.

4 Croisier JL. Factors associated with recurrent hamstring injuries. Sports Med 2004;34:681-95.

5 Brooks JH, Fuller CW, Kemp SP, et al. Epidemiology of injuries in English professional rugby union: part 1 match injuries. Br J Sports Med 2005;39:757-66.

6 Brooks JH, Fuller CW, Kemp SP, et al. Epidemiology of injuries in English professional rugby union: part 2 training Injuries. $\mathrm{Br}$ J Sports Med 2005;39:767-75.
7 Garrett WE Jr. Muscle strain injuries. Am J Sports Med 1996;24(6 Suppl):S2-8.

8 Engebretsen L, Soligard T, Steffen K, et al. Sports injuries and illnesses during the London Summer Olympic Games 2012. Br J Sports Med 2013;47:407-14.

9 Alonso JM, Edouard $\mathrm{P}$, Fischetto $\mathrm{G}$, et al. Determination of future prevention strategies in elite track and field: analysis of Daegu 2011 IAAF Championships injuries and illnesses surveillance. Br J Sports Med 2012:46:505-14.

10 Orchard J, Best TM. The management of muscle strain injuries: an early return versus the risk of recurrence. Clin J Sport Med 2002;12:3-5.

11 Petersen J, Thorborg K, Nielsen MB, et al. Acute hamstring injuries in Danish elite football: a 12-month prospective registration study among 374 players. Scand J Med Sci Sports 2010;20:588-92.

12 De Vos RJ, Reurink G, Goudswaard GJ, et al. Clinical findings just after return to play predict hamstring re-injury, but baseline MRI findings do not. Br J Sports Med 2014;48:1377-84.

13 Arnason A, Andersen TE, Holme I, et al. Prevention of hamstring strains in elite soccer: an intervention study. Scand J Med Sci Sports 2008;18:40-8.

14 Askling CM, Tengvar M, Saartok T, et al. Acute first-time hamstring strains during high-speed running: a longitudinal study including clinical and magnetic resonance imaging findings. Am J Sports Med 2007;35:197-206.

15 Askling CM, Tengvar M, Saartok T, et al. Proximal hamstring strains of stretching type in different sports: injury situations, clinical and magnetic resonance imaging characteristics, and return to sport. Am J Sports Med 2008;36:1799-804.

16 Croisier JL, Ganteaume S, Binet J, et al. Strength imbalances and prevention of hamstring injury in professional soccer players: a prospective study. Am J Sports Med 2008;36:1469-75.

17 Lehance C, Binet J, Bury T, et al. Muscular strength, functional performances and injury risk in professional and junior elite soccer players. Scand J Med Sci Sports 2009;19:243-51

18 Mendiguchia J, Brughelli M. A return-to-sport algorithm for acute hamstring injuries. Phys Ther Sport 2011;12:2-14.

19 Askling C, Karlsson J, Thorstensson A. Hamstring injury occurrence in elite soccer players after preseason strength training with eccentric overload. Scand I Med Sci Sports 2003;13:244-50.

20 Gabbe BJ, Branson R, Bennell KL. A pilot randomised controlled trial of eccentric exercise to prevent hamstring injuries in community-level Australian Football. J Sci Med Sport 2006;9:103-9.

21 Engebretsen $\mathrm{AH}$, Myklebust $\mathrm{G}$, Holme I, et al. Prevention of injuries among male soccer players: a prospective, randomized intervention study targeting players with previous injuries or reduced function. Am J Sports Med 2008;36:1052-60.

22 Petersen J, Thorborg K, Nielsen MB, et al. Preventive effect of eccentric training on acute hamstring injuries in men's soccer: a cluster-randomized controlled trial. Am J Sports Med 2011;39:2296-303.

23 Moen MH, Reurink G, Weir A, et al. Predicting return to play after hamstring injuries. Br J Sports Med 2014;48:1358-63.

24 Ekstrand J, Hagglund $M$, Walden $M$. Injury incidence and injury patterns in professional football: the UEFA injury study. Br J Sports Med 2011;45:553-8.

25 Mendiguchia J, Alentorn-Geli E, Brughelli M. Hamstring strain injuries: are we heading in the right direction? Br J Sports Med 2012;46:81-5.

26 Mjolsnes R, Arnason A, Osthagen T, et al. A 10-week randomized trial comparing eccentric vs. concentric hamstring strength training in well-trained soccer players. Scand J Med Sci Sports 2004;14:311-17.

27 Thorborg K. Why hamstring eccentrics are hamstring essentials. $\mathrm{Br} /$ Sports Med 2012;46:463-5.

28 Grindstaff TL, Hammill RR, Tuzson AE, et al. Neuromuscular control training programs and noncontact anterior cruciate ligament injury rates in female athletes: a numbers-needed-to-treat analysis. J Ath/ Train 2006;41:450-6.

29 Thelen DG, Chumanov ES, Sherry MA, et al. Neuromusculoskeletal models provide insights into the mechanisms and rehabilitation of hamstring strains. Exerc Sport Sci Rev 2006;34:135-41.

30 Proske $\mathrm{U}$, Morgan $\mathrm{DL}$, Brockett $\mathrm{CL}$, et al. Identifying athletes at risk of hamstring strains and how to protect them. Clin Exp Pharmacol Physiol 2004;31:546-50.

31 Piantadosi S. Clinical trials: a methodologic perspective. New York: Wiley-Interscience, 1997.

32 Sommer A, Zeger SL. On estimating efficacy from clinical trials. Stat Med 1991;10:45-52.

33 Cain LE, Cole SR. Inverse probability-of-censoring weights for the correction of time-varying noncompliance in the effect of randomized highly active antiretroviral therapy on incident AIDS or death. Stat Med 2009;28:1725-38.

34 Sedgwick P. Per protocol analysis. BMJ 2010;340:c1825.

35 Cuzick J, Edwards R, Segnan N. Adjusting for non-compliance and contamination in randomized clinical trials. Stat Med 1997;16:1017-29.

36 Goldman $\mathrm{EF}$, Jones DE. Interventions for preventing hamstring injuries. Cochrane Database Syst Rev 2010(1):CD006782.

37 Moher D, Liberati A, Tetzlaff J, et al. Preferred reporting items for systematic reviews and meta-analyses: the PRISMA statement. Int J Surg 2010;8:336-41.

38 http://www.pedro.fhs.usyd.edu.au. [cited 5 Dec 2013].

39 DerSimonian R, Laird N. Meta-analysis in clinical trials. Control Clin Trials 1986;7:177-88 
40 Higgins JP, Thompson SG. Quantifying heterogeneity in a meta-analysis. Stat Med 2002;21:1539-58

41 Higgins JPT, Green S, eds. Cochrane Handbook for Systematic Reviews of Interventions. The Cochrane Collaboration, 2011.

42 Higgins JP. Commentary: heterogeneity in meta-analysis should be expected and appropriately quantified. Int J Epidemiol 2008;37:1158-60.

43 Poole C. Low P-values or narrow confidence intervals: which are more durable? Epidemiology 2001:12:291-4.

44 Small K, McNaughton L, Greig M, et al. Effect of timing of eccentric hamstring strengthening exercises during soccer training: implications for muscle fatigability. J Strength Cond Res 2009;23:1077-83.

45 Jonhagen $S$, Ackermann $P$, Saartok T. Forward lunge: a training study of eccentric exercises of the lower limbs. J Strength Cond Res 2009:23:972-8.

46 Brughelli M, Mendiguchia J, Nosaka K, et al. Effects of eccentric exercise on optimum length of the knee flexors and extensors during the preseason in professional soccer players. Phys Ther Sport 2010;11:50-5.

47 Engebretsen AH, Myklebust G, Holme I, et al. Intrinsic risk factors for hamstring injuries among male soccer players: a prospective cohort study. Am I Sports Med 2010;38:1147-53.

48 Al-Eisa E. Indicators of adherence to physiotherapy attendance among Saudi female patients with mechanical low back pain: a clinical audit. BMC Musculoskelet Disord 2010:11:124.

49 Kolt GS, McEvoy JF. Adherence to rehabilitation in patients with low back pain. Man Ther 2003:8:110-16.

50 Medina-Mirapeix F, Escolar-Reina P, Gascon-Canovas JJ, et al. Predictive factors of adherence to frequency and duration components in home exercise programs for neck and low back pain: an observational study. BMC Musculoskelet Disord 2009:10:155.
51 McLean SM, Burton M, Bradley L, et al. Interventions for enhancing adherence with physiotherapy: a systematic review. Man Ther 2010;15:514-21.

52 Jack K, McLean SM, Moffett JK, et al. Barriers to treatment adherence in physiotherapy outpatient clinics: a systematic review. Man Ther 2010;15:220-8.

53 Hayden JA, van Tulder MW, Tomlinson G. Systematic review: strategies for using exercise therapy to improve outcomes in chronic low back pain. Ann Intern Med 2005; 142:776-85.

54 Chan DK, Lonsdale C, Ho PY, et al. Patient motivation and adherence to postsurgery rehabilitation exercise recommendations: the influence of physiotherapists' autonomy-supportive behaviors. Arch Phys Med Rehabil 2009;90:1977-82.

55 Friedrich $\mathrm{M}$, Gittler $\mathrm{G}$, Halberstadt $\mathrm{Y}$, et al. Combined exercise and motivation program: effect on the compliance and level of disability of patients with chronic low back pain: a randomized controlled trial. Arch Phys Med Rehabil 1998;79:475-87.

56 Soligard T, Myklebust G, Steffen K, et al. Comprehensive warm-up programme to prevent injuries in young female footballers: cluster randomised controlled trial. $B M J$ 2008;337:a2469.

57 Soderman $\mathrm{K}$, Werner $\mathrm{S}$, Pietila $\mathrm{T}$, et al. Balance board training: prevention of traumatic injuries of the lower extremities in female soccer players? A prospective randomized intervention study. Knee Surg Sports Traumatol Arthrosc 2000;8:356-63.

58 Frank B, Register-Mihalik J, Marshall S, et al. A coaching workshop improves coach intention but does not translate to implementation of a acl injury prevention program. Br J Sports Med 2014;48:595.

59 Joy EA, Taylor JR, Novak MA, et al. Factors influencing the implementation of anterior cruciate ligament injury prevention strategies by girls soccer coaches. J Strength Cond Res 2013;27:2263-9. 